\title{
Maternal Factors and Utilization of the Antenatal Care Services during Pregnancy Associated with Low Birth Weight in Rural Nepal: Analyses of the Antenatal Care and Birth Weight Records of the MATRI-SUMAN Trial
}

\author{
Dilaram Acharya ${ }^{1}{ }^{\mathbb{D}}$, Jitendra Kumar Singh ${ }^{2}$, Rajendra Kadel ${ }^{3}$, Seok-Ju Yoo ${ }^{1}$, Ji-Hyuk Park ${ }^{1} \mathbb{C}$ \\ and Kwan Lee $1, *(\mathbb{D})$ \\ 1 Department of Preventive Medicine, College of Medicine, Dongguk University, Gyeongju 38066, Korea; \\ dilaramacharya123@gmail.com (D.A.); medhippo@hanmail.net (S.-J.Y.); skeyd@naver.com (J.-H.P.) \\ 2 Department of Community Medicine and Public Health, Janaki Medical College, Tribhuvan University, \\ Janakpur 44618, Nepal; jsingdj@gmail.com \\ 3 Personal Social Services Research Unit, London School of Economics and Political Science, \\ London, WC2A2AE, UK; r.kadel@lse.ac.uk \\ * Correspondence: kwaniya@dongguk.ac.kr; Tel.: +82-54-770-2408; Fax: +82-54-770-2438
}

Received: 9 October 2018; Accepted: 31 October 2018; Published: 3 November 2018

\begin{abstract}
Low birth weight (LBW) remains a major public health problem in developing countries, including Nepal. This study was undertaken to examine the association between LBW and maternal factors and antenatal care service utilization, in rural Nepal, using data obtained for a capacity-building and text-messaging intervention, designed to enhance maternal and child health service utilization among pregnant women, in rural Nepal ("MATRI-SUMAN"). The study used a clustered randomized controlled design and was conducted during 2015-2016. We investigated maternal and antenatal care service utilization determinants of LBW, using a logistic regression model. Of the four hundred and two singleton babies, included in the present study, seventy-eight (19.4\%) had an LBW (mean (SD), 2210.64 (212.47)) grams. It was found that Dalit caste/ethnicity, illiteracy, manual labor, a female baby, and having more than four family members were significantly positively associated with LBW. In addition, mothers who did not visit an antenatal care (ANC) unit, visited an ANC $<4$ times, did not take iron and folic acid (IFA), de-worming tablets, and mothers that did not consume additional food, during pregnancy, were more likely to have an LBW baby, than their counterparts. The MATRI-SUMAN intervention and availability of a kitchen garden at home, were found to reduce the risk of LBW. Nepalese child survival policies and programs should pay attention to these maternal and antenatal care service utilization factors, while designating preventive strategies to improve child health outcomes.
\end{abstract}

Keywords: antenatal care services; low birth weight; maternal factors; Nepal

\section{Introduction}

Low birth weight (LBW) has been defined as a birth weight $<2500$ grams [1]. In 2013, an estimated 16 per cent ( 22 million) of all babies born globally, had LBW and $96 \%$ of these babies were born in developing countries [1,2]. In Nepal, a recent study, using the Nepal Demographic and Health Survey 2011 data showed that the prevalence of LBW was 15.4\% [3]. It was noted that LBW babies are at a greater risk of dying in the first year of life [4]. LBW can result from either intra-uterine growth restriction, small-for-gestational-age (born before 37 weeks of gestation) or a combination 
of the two $[1,5,6]$. The majority of LBW cases in developing countries are due to intra-uterine growth retardation, while pre-term birth is common in the developed countries [7]. In addition to adverse consequences, such as, increased neonatal morbidity and mortality, inhibition of growth and cognitive development, and an increased risk of chronic disease development, later in life, LBW also has substantial cost burdens on health care systems and society [1,8-10]. Several recent studies have concluded that LBW increases the risk of non-communicable diseases, such as, diabetes and cardiovascular conditions, later in life [11-13]. Moreover, LBW has been reported to be associated with negative effects on long-term cognitive and motor development, and on decision-making [14].

Numerous direct and indirect factors have been associated with LBW [15-17]. Socio-demographic and economic characteristics, age, household food security, and the use of maternity services are some of the indirect determinants identified, whereas race, maternal height and pre-pregnancy weight, gestational weight gains, calorie intake during pregnancy, perinatal morbidity, parity, infant's sex, alcohol and cigarette consumption during pregnancy, and prior history of prematurity, among others, have been reported to be direct determinants [16-19].

Few community-based studies have assessed the risk factors of LBW in Nepal. In a recent Nepalese study on nationally representative samples, it was reported that $12 \%$ of infants had an LBW, and that mothers who did not attend antenatal care units, did not take iron tablets during pregnancy, and resided in the westernmost region of the country were at a significant risk of having an LBW baby [20]. Given that the majority (65\%) of births took place at home [21] and no significant change was detected between the percentages of LBW babies observed in the 2011 and the 2016 Demographic and Health Surveys ( $12 \%$ in both surveys) [22], LBW is now considered an important public health problem. Therefore, further understanding of the risk factors of LBW is required to support the early identification of those at risk and facilitate the implementations of evidence-specific interventions to reduce the long-standing problem of LBW in Nepal. To fulfill the existing evidence gap, we aimed to examine the association between low birth weight and maternal factors and utilization of antenatal care services, in rural Nepal.

\section{Materials and Methods}

\subsection{Study Design, Population, and Sampling}

We used data from a capacity-building and text-messaging intervention that was developed to enhance maternal and child health service utilization among pregnant women, in rural Nepal ("MATRI-SUMAN"), which was conducted using a clustered randomized controlled design. Pregnant women aged 15-49 years, in their second trimester (13-28 weeks of gestation), from fifty-two clusters (wards) of six village development committees (VDCs), from the Dhanusha district, were selected for the MATRI-SUMAN trial, using multistage cluster sampling method. During the first stage of the MATRI-SUMAN trial, two healthcare facilities were selected as a primary sampling unit. In the second stage, six of the twelve VDCs, in the catchment areas of these two healthcare facilities, were selected, using a stratified random sampling method. In the intervention group, Female Community Health Volunteers (FCHVs) were trained in capacity development skills through reinforcement training, supervision, and monitoring of maternal and child health care services. Pregnant women received periodic health promotion texts about maternal and child health $(\mathrm{MCH})$ components, via a mobile messaging service, while participants in the control group received the usual care. Details of the study design have been reported in a previously published paper [23].

A total of four hundred and twenty-six pregnant women aged 15-49 participated in the MATRI-SUMAN trial. Of the four hundred and twenty-six participants interviewed at baseline, four hundred and thirteen of them were approached at postnatal follow-up and the remainder were not available for follow-up (of the thirteen missing cases, seven had moved to their parental home and six had a miscarriage). Additionally, we were not able to measure the birth weights, within the stipulated time, for eight cases and three mothers had still births, giving us a sample of four hundred 
and two mothers with live birth babies. Among the four hundred and two cases, seventy-eight newborn babies had low birth weight and the remaining three hundred and twenty-four babies had normal birth weight. We included four hundred and two live birth cases for the statistical analyses (Figure 1). The criteria we used for data selection were as follows; singleton live birth with birth weight measured within one hour of birth, for institutional delivery, and within forty-eight hours of birth, for home delivery. A pan balance was used to measure birth weights in a health facility (hospital/birthing center) and a color-coded spring balance was used by a local FCHV, for the home deliveries. Three sets of validated questionnaires that were adopted from the Nepal Demographic and Population Health Survey, 2011, were used to collect information [21]. These questionnaires addressed; (i) the socio-demographic and household characteristics of pregnant women, (ii) obstetric history of pregnant women, and iii) newborn information. The study data contained information on maternal factors, newborn weight, and maternal utilization of antenatal care services.

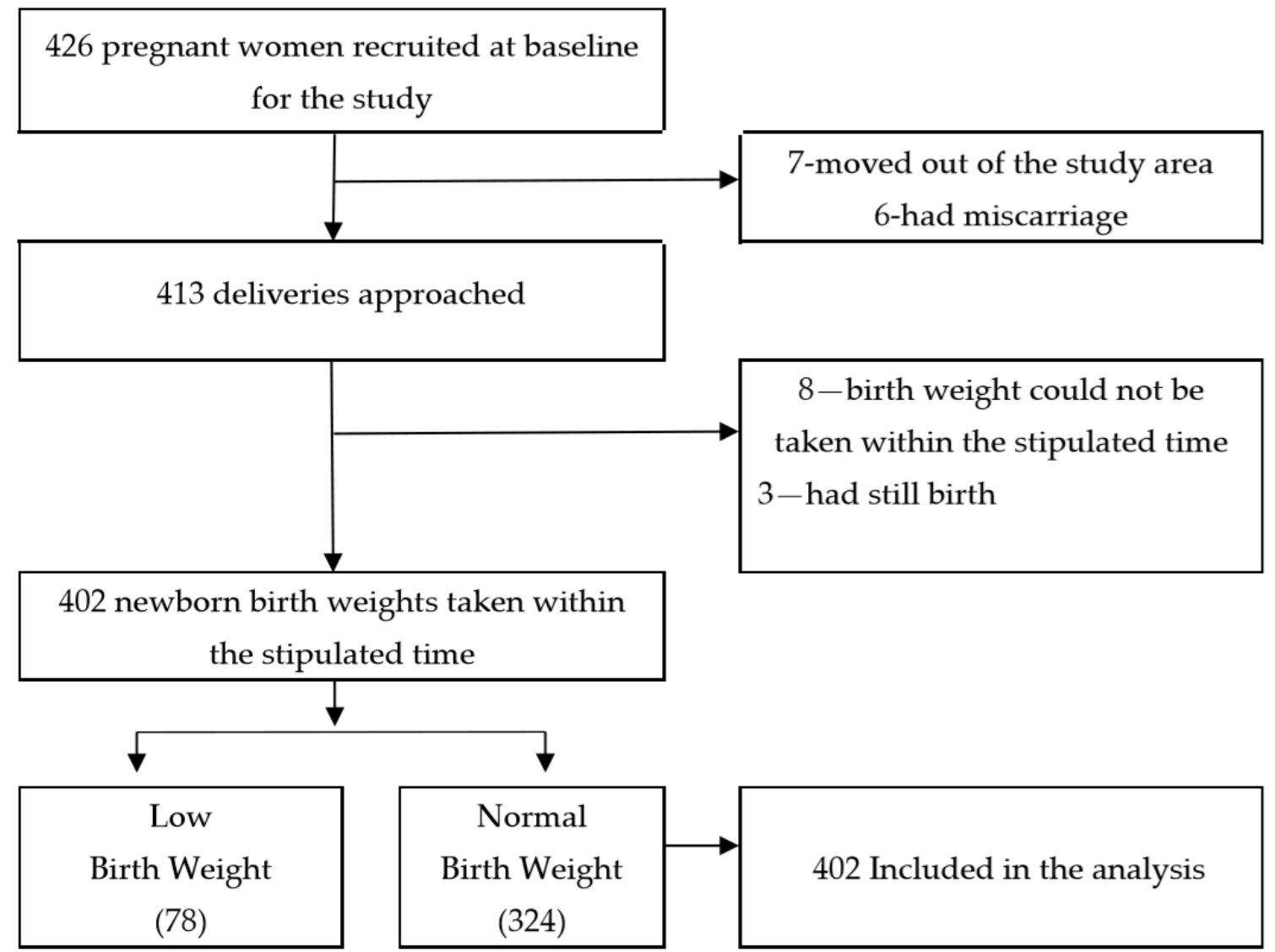

Figure 1. Flow chart showing the process of sample selection.

\subsection{Definition of Variables}

A low birth weight (LBW) was defined as one $<2500$ grams. Birth weights were classified as LBW ( $<2500$ grams) or (ii) normal ( $\geq 2500$ grams or more), and birth weight was the dependent variable in the present study. Independent variables examined were chosen, as previously described [24]. Age was classified as: (i) $<20$ years, (ii) 20-34 years, or (iii) $\geq 35$ years. Ethnicity was classified as, (i) upper caste group-Brahmin, Chhetri, and other relatively-advantaged Terai caste groups (Yadav, Shaha, Thakur), (ii) Adibasi/Janajati- Janajati or indigenous groups, and (iii) Dalit (relatively disadvantaged) [25]. Education was recorded as number of completed years of education and classified as, (i) illiterate-no education, (ii) primary-1 to 5 years of education, and (iii) secondary and above ( $\geq 6$ years of education) [24]. Occupations were categorized as, (i) business or private/government work or involved in household work; (ii) agricultural work on own farms, and (iii) manual labor. 
Incomes were classified using monthly family incomes and categorized using terciles, (i) 1st tercile (income $<14,333$ Nepalese Rupees/month (NRs/month), (ii) 2nd tercile (14334-23666 NRs/month), of (iii) 3rd tercile ( $>23666 \mathrm{NRs} /$ month). Parity was categorized as primiparous or multiparous. Head of household was included as an indicator of maternal autonomy and classified as, (i) the pregnant women herself or (ii) husband/mother-in-law, father-in-law, or others. Personal dietary habits were recorded as vegetarian or non-vegetarian. Family size was classified as $\leq 4$ or $>4$. Number of living rooms were classified as, (i) sufficient if there were not $>2$ family members sleeping per room or (ii) insufficient if $>2$ family members slept in a room. Reponses regarding the presence of domestic animals in a household and of a home kitchen garden were recorded as "yes" or "no". Antenatal care (ANC) visits were categorized as, (i) no ANC visit, (ii) $<4$ ANC visits, and (iii) $\geq 4$ ANC visits. Iron and folic acid (IFA) consumption and tetanus and diphtheria (TD) immunization were recorded as "yes" or "no". Similarly, other components of antenatal care (like de-worming, adequate rest, and sleep (Eight hours of sleep during night time and two hours during day time), additional food (defined as one extra meal per day as recommended by the government of Nepal) were also coded as "yes" or "no".

\subsection{Statistical Analysis}

The Chi-square test (unadjusted) was used to examine the association between the LBW and the categorical independent variables of interest. All factors, significant by the unadjusted analysis, were included in the multiple logistic regression analysis to control for confounding effects. Unadjusted and adjusted odds ratios, with their $95 \%$ confidence intervals (CI), were reported. Variables having $p$-value $\leq 0.1$ were entered in a final multivariate logistic regression model with a backward elimination and the analysis results with a $p$-value of $<0.05$ was considered statistically significant. Statistical analysis was performed using the Statistical Package for Social Sciences version 21.0 (SPSS, IBM, Armonk, NY, USA).

\subsection{Ethical Considerations}

The study protocol was approved by the Nepal Health Research Council (approval no: 101), the Ethics Committee of the Institute of Medical Sciences, Banaras Hindu University, India (approval no: ECR/ 526/Inst/UP/2014 Dt.31.1.14) and District Public Health Office, Dhanusha, Nepal (Ref. 2245). Additional ethical approval for the data analysis was obtained from the Institutional Review Board of Janaki Medical College, Nepal. The study objectives and procedures were explained, and a written informed consent was taken from each participant, before the data collection process began. Personal identifiers were removed before data analysis.

\section{Results}

\subsection{Status of Birth Weight}

Figure 2 shows the distribution of average birth weight (with standard deviations) of the newborn babies. The average birth weight for the LBW babies was 2210.64 grams with a standard deviation of 212.47 grams, whereas the mean birth weight for the normal weight babies was 3054 grams with a standard deviation of 424 grams. Mean difference in birth weight between an LBW baby and a normal baby was found to be significant (843.24 gm; $p<0.0001,95 \%$ CI: 745.94-940.55). 


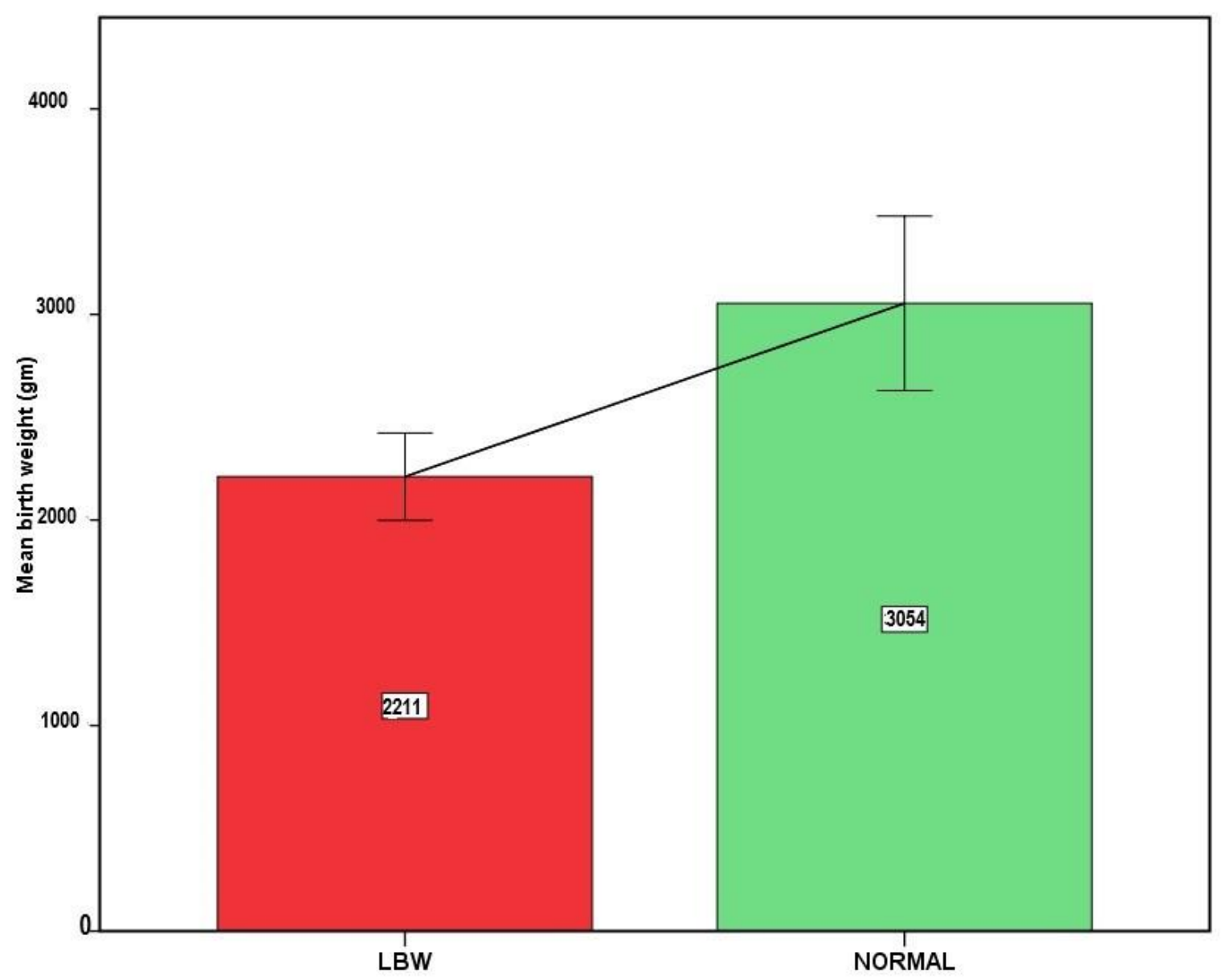

Standard Deviation: $+/-1$ SD

Figure 2. Status of birth weights among newborns.

\subsection{Maternal Factors and Utilization of Antenatal Care Services}

Table 1 summarizes the maternal characteristics. 402 mother-child pairs were analyzed and the majority of mothers were 20-34 years old (69.2\%), upper caste (61.2\%), and had a primary or greater education level (75.2\%). Almost a half (49.8\%) worked in the service/business/household sectors, the majority $(65.6 \%)$ had second and third terciles of family income, most maternal in-laws/husbands were family heads $(77.6 \%)$, slightly more than half $(51.5 \%)$ were from the MATRI-SUMAN intervention area, the majority were from the Terai origin by birth $(71.6 \%)$, non-vegetarian $(79.6 \%)$, multiparous $(60.9 \%)$, slightly more than half ( $52.5 \%)$ gave birth to a female baby and had four or fewer family members (52.7\%), just over one-third (39.6\%) had domestic animals, and the majority $(66.4 \%)$ had a kitchen garden. Maternal factors, such as, caste/ethnicity, educational status, occupation, family income, head of the family, area of residence, parity, number of family members in a household, adequacy of living rooms for the family, and use of a kitchen garden were found to be significantly associated with LBW (Table 1). 
Table 1. Association between maternal factors and low birth weight (LBW) *.

\begin{tabular}{|c|c|c|c|c|}
\hline \multirow{2}{*}{ Variables } & \multirow{2}{*}{$n=402(\%)$} & \multicolumn{2}{|c|}{ Low Birth Weight } & \multirow{2}{*}{$p$-Value } \\
\hline & & Yes, $n=78(\%)$ & No, $n=324(\%)$ & \\
\hline \multicolumn{5}{|l|}{ Age } \\
\hline$<20$ year & $91(22.6)$ & $20(25.6)$ & $71(21.9)$ & 0.674 \\
\hline 20-34 year & $278(69.2)$ & $53(67.9)$ & $225(69.5)$ & \\
\hline$\geq 35$ years & $33(8.2)$ & $5(6.4)$ & $28(8.6)$ & \\
\hline \multicolumn{5}{|l|}{ Caste/ethnicity } \\
\hline Upper caste group & $246(61.2)$ & 27 (34.6) & $219(67.6)$ & $<0.0001$ \\
\hline Adibasi/Janajati & $89(22.1)$ & $19(24.4)$ & 70 (21.6) & \\
\hline Dalit & $67(16.7)$ & $32(41.0)$ & $35(10.8)$ & \\
\hline \multicolumn{5}{|l|}{ Educational status } \\
\hline Illiterate & $100(24.8)$ & $46(59.0)$ & $54(16.7)$ & $<0.0001$ \\
\hline Primary & $145(36.1)$ & $21(26.9)$ & $124(38.3)$ & \\
\hline Secondary and above & $157(39.1)$ & $11(14.1)$ & $146(45.0)$ & \\
\hline \multicolumn{5}{|l|}{ Occupation } \\
\hline Labor & $75(18.7)$ & $36(46.2)$ & $39(12.0)$ & $<0.0001$ \\
\hline Agricultural work & $127(31.6)$ & $24(30.8)$ & $103(31.8)$ & \\
\hline Service/business/HH works & $200(49.8)$ & $18(23.0)$ & $182(56.2)$ & \\
\hline \multicolumn{5}{|l|}{ Family income } \\
\hline 1st tercile & $138(34.3)$ & $39(50.0)$ & $99(30.5)$ & $<0.0001$ \\
\hline 2nd tercile & $128(31.8)$ & $26(33.3)$ & $102(31.5)$ & \\
\hline 3rd tercile & $136(33.8)$ & $13(16.7)$ & $123(38.0)$ & \\
\hline \multicolumn{5}{|l|}{ Head of family } \\
\hline Herself & $90(22.4)$ & $10(12.8)$ & $80(24.7)$ & 0.024 \\
\hline Others (In-laws/ Husband) & $312(77.6)$ & $68(87.2)$ & $244(75.3)$ & \\
\hline \multicolumn{5}{|l|}{$\begin{array}{c}\text { Resided in MATRI-SUMAN } \\
\text { intervention area }\end{array}$} \\
\hline Yes & $207(51.5)$ & $31(39.7)$ & $176(54.3)$ & 0.021 \\
\hline No & $195(48.5)$ & $47(60.3)$ & $148(45.7)$ & \\
\hline \multicolumn{5}{|l|}{ Origin of residence } \\
\hline Terai & $288(71.6)$ & $51(65.4)$ & $237(73.1)$ & 0.172 \\
\hline Hill & $114(28.4)$ & $27(34.6)$ & $87(26.9)$ & \\
\hline \multicolumn{5}{|l|}{ Dietary habit } \\
\hline Non-vegetarian & $320(79.6)$ & $63(80.8)$ & $257(79.3)$ & 0.776 \\
\hline Vegetarian & $82(20.4)$ & $15(19.2)$ & $67(20.7)$ & \\
\hline \multicolumn{5}{|l|}{ Parity } \\
\hline Primi & $157(39.1)$ & $22(28.2)$ & 135 (41.7) & 0.029 \\
\hline Multi & $245(60.9)$ & $56(71.8)$ & $189(58.3)$ & \\
\hline \multicolumn{5}{|l|}{ Sex of Child } \\
\hline Male & $191(47.5)$ & $28(35.9)$ & $163(50.3)$ & 0.022 \\
\hline Female & $211(52.5)$ & $50(64.1)$ & $161(49.7)$ & \\
\hline \multicolumn{5}{|l|}{ Family size } \\
\hline 4 and less person & $212(52.7)$ & $12(15.4)$ & $200(61.7)$ & $<0.0001$ \\
\hline$>4$ persons & $190(47.3)$ & $66(84.6)$ & $124(38.3)$ & \\
\hline \multicolumn{5}{|l|}{ Living room in family } \\
\hline Insufficient & $176(43.8)$ & $57(73.1)$ & $119(36.7)$ & $<0.0001$ \\
\hline Sufficient & $226(56.2)$ & $21(26.9)$ & $205(63.3)$ & \\
\hline \multicolumn{5}{|l|}{ Domestic animals } \\
\hline Yes & $159(39.6)$ & $25(32.1)$ & $134(41.4)$ & 0.131 \\
\hline No & $243(60.4)$ & $53(67.9)$ & $190(58.6)$ & \\
\hline \multicolumn{5}{|l|}{ Kitchen garden } \\
\hline Yes & $267(66.4)$ & $19(24.4)$ & $248(76.5)$ & $<0.0001$ \\
\hline No & 135 (33.6) & $59(75.6)$ & $76(23.5)$ & \\
\hline
\end{tabular}

${ }^{*}$ Chi-square test was applied and $p$-values $<0.05$ were considered statistically significant. 
Regarding ANC service utilization, more than half (59.7\%) visited four or more ANCs, $58.5 \%$ consumed recommended doses of iron and folic acid tablets, $81.6 \%$ were properly immunized for tetanus and diphtheria, $81.3 \%$ consumed de-worming tablets, $84.3 \%$ got adequate rest and sleep, and about one in four received additional food during pregnancy. Utilization of the antenatal care services during pregnancy (as indicated by the number of antenatal care visits), consumption of recommended doses of iron and folic acid (IFA), immunization for tetanus and diphtheria, consumption of deworming tablets, adequate rest and sleep, and additional food intake during pregnancy, were significantly associated with LBW (Table 2).

Table 2. Association between the utilization of selected antenatal care services and low birth weight (LBW) *.

\begin{tabular}{|c|c|c|c|c|}
\hline \multirow{2}{*}{ Variables } & \multirow{2}{*}{$n=402(\%)$} & \multicolumn{2}{|c|}{ Low Birth Weight } & \multirow{2}{*}{$p$-Value } \\
\hline & & Yes, $n=78(\%)$ & No, $n=324(\%)$ & \\
\hline \multicolumn{5}{|c|}{ ANC visit-end } \\
\hline No & $35(8.7)$ & $14(17.9)$ & $21(6.5)$ & 0.002 \\
\hline$<4 \mathrm{ANC}$ & $127(31.6)$ & $29(37.2)$ & $98(30.2)$ & \\
\hline 4 or More & $240(59.7)$ & $35(44.9)$ & $205(63.3)$ & \\
\hline \multicolumn{5}{|c|}{ Consumption of recommended dose of Iron and folic acid (IFA) } \\
\hline Yes & $235(58.5)$ & $34(43.6)$ & $201(62.0)$ & 0.003 \\
\hline No & $167(41.5)$ & $44(56.4)$ & $123(38.0)$ & \\
\hline \multicolumn{5}{|c|}{ Immunized with recommended dose of Tetanus and diphtheria (TD) } \\
\hline Yes & $328(81.6)$ & $48(61.6)$ & $280(86.4)$ & $<0.0001$ \\
\hline No & $74(18.4)$ & $30(38.4)$ & $44(13.6)$ & \\
\hline \multicolumn{5}{|c|}{ Consumed de-worming tablet } \\
\hline Yes & $327(81.3)$ & $47(60.3)$ & $280(86.4)$ & $<0.0001$ \\
\hline No & $75(18.7)$ & $31(39.7)$ & $44(13.6)$ & \\
\hline \multicolumn{5}{|c|}{ Adequate rest and sleep taken } \\
\hline SYes & $339(84.3)$ & $59(75.6)$ & $280(86.4)$ & 0.019 \\
\hline No & $63(15.7)$ & $19(24.4)$ & 44 (13.6) & \\
\hline \multicolumn{5}{|c|}{ Additional food intake } \\
\hline Yes & 99 (24.6) & $47(60.3)$ & $52(16.0)$ & $<0.0001$ \\
\hline No & $303(75.4)$ & 31 (39.7) & $272(84.0)$ & \\
\hline
\end{tabular}

${ }^{*}$ Chi-square test was applied and $p$-values of $<0.05$ were considered statistically significant.

\subsection{Associations between Low Birth Weight and Maternal Factors and the Utilization of Antenatal Care Services}

Table 3 shows the results of multivariate analyses on the determinants of LBW. Statistically significant factors that influenced LBW are listed in Tables 1 and 2, and these were included in the multiple logistic regression model. Maternal socio-demographic factors, such as caste/ethnicity, educational status, occupation, family size, and other factors, such as sex of child, having access to a kitchen garden, and living in the MATRI-SUMAN intervention area were significantly associated with LBW. Similarly, the utilization of antenatal care services as indicated by number of ANC visits, taking recommended doses of IFA tablets and de-worming tablets, and additional food intake during pregnancy, were significantly associated with LBW. 
Table 3. Relations between low birth weight (LBW) and maternal factors and the utilization of antenatal care services during pregnancy, by logistic regression analysis*.

\begin{tabular}{|c|c|c|c|c|}
\hline Variables & OR $(95 \% \mathrm{CI})$ & $p$-Value & aOR $(95 \% \mathrm{CI})$ & $p$-Value \\
\hline \multicolumn{5}{|c|}{ Maternal factors } \\
\hline \multicolumn{5}{|l|}{ Intervention area } \\
\hline Yes & $0.55(0.34-1.0)$ & 0.022 & $0.37(0.16-0.83)$ & 0.009 \\
\hline No & 1.0 (ref.) & & 1.0 (ref.) & \\
\hline \multicolumn{5}{|l|}{ Caste/ethnicity } \\
\hline Dalit & $7.4(3.9-13.8)$ & 0.0001 & $4.2(1.7-10.4)$ & 0.0001 \\
\hline Adibasi/Janajati & $2.2(1.1-4.2)$ & 0.0001 & $1.8(0.8-5.1)$ & 0.216 \\
\hline Upper caste group & 1.0 (ref.) & - & 1.0 (ref.) & - \\
\hline \multicolumn{5}{|l|}{ Educational status } \\
\hline Illiterate & $11.3(5.4-23.4)$ & 0.0001 & $8.1(2.9-22.4)$ & 0.0001 \\
\hline Primary & $2.2(1.0-4.8)$ & 0.0001 & $1.6(0.9-8.6)$ & 0.217 \\
\hline Secondary and above & 1.0 (ref.) & - & 1.0 (ref.) & - \\
\hline \multicolumn{5}{|l|}{ Occupation } \\
\hline Labor & $9.3(4.8-18.1)$ & 0.001 & $5.9(1.6-21.1)$ & 0.006 \\
\hline Agricultural work & $2.3(1.2-4.5)$ & 0.011 & $1.7(0.5-5.3)$ & 0.332 \\
\hline Service/ business / HH works & 1.0 (ref.) & - & 1.0 (ref.) & - \\
\hline \multicolumn{5}{|l|}{ Family income } \\
\hline 1st tercile & $3.7(1.8-7.3)$ & 0.0001 & $1.1(0.5-2.9)$ & 0.761 \\
\hline 2nd tercile & $2.4(1.1-4.9)$ & 0.016 & $1.4(0.3-1.9)$ & 0.618 \\
\hline 3rd tercile & 1.0 (ref.) & - & 1.0 (ref.) & - \\
\hline \multicolumn{5}{|l|}{ Head of family } \\
\hline Others (In-laws / Husband) & $2.2(1.0-4.5)$ & 0.027 & $1.9(0.6-5.5)$ & 0.206 \\
\hline Herself & 1.0 (ref.) & - & 1.0 (ref.) & - \\
\hline \multicolumn{5}{|l|}{ Parity } \\
\hline Multi & $1.8(1.0-3.1)$ & 0.030 & $1.1(0.5-2.4)$ & 0.758 \\
\hline Primi & 1.0 (ref.) & - & 1.0 (ref.) & - \\
\hline \multicolumn{5}{|l|}{ Sex of child } \\
\hline Female & $1.8(1.0-3.0)$ & 0.023 & $2.0(1.0-4.1)$ & 0.047 \\
\hline Male & 1.0 (ref.) & - & 1.0 (ref.) & - \\
\hline \multicolumn{5}{|l|}{ Family size } \\
\hline$>4$ persons & $8.8(4.6-17.0)$ & $<0.0001$ & $5.6(2.3-13.5)$ & $<0.0001$ \\
\hline 4 and less person & 1.0 (ref.) & - & 1.0 (ref.) & - \\
\hline \multicolumn{5}{|l|}{ Living room in family } \\
\hline Insufficient & $5.0(2.9-8.8)$ & $<0.0001$ & $1.2(0.4-3.5)$ & 0.664 \\
\hline Sufficient & 1.0 (ref.) & - & 1.0 (ref.) & - \\
\hline \multicolumn{5}{|l|}{ Kitchen garden } \\
\hline Yes & $0.09(0.05-0.17)$ & $<0.0001$ & $0.15(0.06-0.37)$ & $<0.0001$ \\
\hline No & 1.0 (ref.) & - & 1.0 (ref.) & - \\
\hline \multicolumn{5}{|c|}{ Utilization of antenatal care services during pregnancy } \\
\hline \multicolumn{5}{|c|}{ ANC visit } \\
\hline No & $3.9(1.8-8.3)$ & $<0.0001$ & $5.1(1.1-22.6)$ & 0.029 \\
\hline$<4 \mathrm{ANC}$ & $1.7(1.0-3.0)$ & $<0.0010$ & $3.4(1.1-10.2)$ & 0.027 \\
\hline 4 and more ANC & 1.0 (ref.) & - & 1.0 (ref.) & - \\
\hline \multicolumn{5}{|c|}{ Consumption of recommended dose of Iron and folic acid (IFA) } \\
\hline No & $2.1(1.2-3.4)$ & 0.003 & $3.0(1.1-8.2)$ & 0.025 \\
\hline Yes & 1.0 (ref.) & - & 1.0 (ref.) & - \\
\hline \multicolumn{5}{|c|}{ Immunized with recommended dose of Tetanus and diphtheria (TD) } \\
\hline No & $3.9(2.2-6.9)$ & 0.0001 & $2.2(0.5-10.0)$ & 0.295 \\
\hline Yes & 1.0 (ref.) & - & 1.0 (ref.) & - \\
\hline \multicolumn{5}{|c|}{ Consumed de-worming tablet } \\
\hline No & $4.1(2.4-7.3)$ & 0.0001 & $3.1(1.0-13.8)$ & 0.049 \\
\hline Yes & 1.0 (ref.) & - & 1.0 (ref.) & - \\
\hline & Adequate rest & leep taken & & \\
\hline No & $2.0(1.1-3.7)$ & 0.020 & $1.5(0.5-4.8)$ & 0.412 \\
\hline Yes & 1.0 (ref.) & - & 1.0 (ref.) & - \\
\hline & Additional & intake & & \\
\hline No & $7.9(4.6-13.6)$ & 0.0001 & $3.6(1.3-9.4)$ & 0.008 \\
\hline Yes & 1.0 (ref.) & - & 1.0 (ref.) & - \\
\hline
\end{tabular}

* All variables having $p$-value $\leq 0.1$ were entered in a final multivariate logistic regression model and the statistical significance was considered for $p$-value $<0.05$. Ref.: reference. 
Mothers from the Dalit caste/ethnicity group were four-times more likely (aOR 4.2; 95\% CI (1.7-10.4)) to have an LBW baby than mothers from the Adibasi/Janajati and upper-caste groups. Similarly, illiterate mothers were eight-times more likely (aOR 8.1; 95\% CI (2.9-22.4)) to have an LBW baby than literate mothers. Mothers that performed manual work were at greater risk (aOR $5.9 ; 95 \% \mathrm{CI}$ (1.6-21.1)) of having an LBW baby than mothers with an agricultural or service/business/household occupation. Female children were twice more likely (aOR 2.0; 95\% CI (1.0-4.1)) to be born with an LBW than male children. Mothers who had more than four family members had higher odds of having LBW babies (aOR 5.6; 95\% CI (2.3-13.5)) than mothers who had four or fewer number of family members. Mothers in the MATRI-SUMAN intervention area were less likely (aOR 0.37; 95\% CI (0.16-0.83)) to have an LBW baby than mothers not in the intervention area. Access to a kitchen garden reduced the risk (aOR 0.15 ; $95 \% \mathrm{CI}(0.06-0.37)$ ) of having an LBW baby.

Mothers who had not visited ANCs were five-times more likely (aOR 5.1; 95\% CI (1.1-22.6)) to have an LBW baby, and mothers who visited an ANC, less than four times, were three-times more likely (aOR 3.4; 95\% CI (1.1-10.2)) to have an LBW baby than the mothers who visited four or more times. Not taking IFA tablets during pregnancy increased the risk (aOR 3.0; 95\% CI (1.1-8.2)) of an LBW baby. Mothers who did not consume de-worming tablets during pregnancy were three-times more likely (aOR 3.1; 95\% CI (1.0-13.8)) to have an LBW baby. Finally, not taking additional food during pregnancy was found to increase the risk (aOR 3.6; 95\% CI (1.3-9.4)) of delivering an LBW baby.

\section{Discussion}

We found a wide range of maternal factors, that is, the Dalit caste/ethnicity, illiteracy, occupation as a manual laborer, having four or more family members, and birth of a female child were significantly positively associated with an LBW, and that those with a kitchen garden and those who resided in the intervention area of the MATRI-SUMAN trial area were less likely to have LBW babies. In addition, lack of utilization of antenatal care services (as indicated by no ANC visit), fewer than four ANC visits, not consuming the recommended doses of IFA and de-worming tablets, and not consuming additional food during pregnancy, increased the risk of an LBW baby.

Our study revealed that babies born to mothers from the Dalit caste/ethnic group were at a greater risk of having an LBW baby than those from the Adibasi/Janajati and upper caste/ethnic group. Several previous studies have also observed relations between ethnicity and LBW [26-28]. The Dalit ethnic group in Nepal are one of the most deprived and marginalized, many lack basic amenities, and fail to utilize available maternity care services [25,29]. Results from previous studies have consistently demonstrated that Dalit women are at risk of having LBW babies in Nepal [30,31]. Like many other studies $[17,18,32,33]$, we also found that illiterate mothers were more likely to give birth to LBW babies, which may be due to a lesser use of antenatal care services because of a lack of knowledge and decision-making power [34]. Lower maternal education has been previously reported to be associated with poor utilization of prenatal care services and low nutritious food intake, and thus, to increase the risk of LBW babies $[35,36]$. Additionally, adolescent marriage and pregnancy is one of the major causes of LBW babies and is prevalent among illiterate women [37]. Increasing girls' education levels, female empowerment, raising health awareness through mass media, and nutritional counseling during antenatal check-ups, would help a lot to address the long-standing problem of LBW, in Nepal $[18,34,38]$.

In the present study, maternal occupation as a manual laborer, four or more family members in a household, and birth of female child were found to increase the risk of LBW, while access to a kitchen garden or residing in the MATRI-SUMAN intervention area reduced the risk of LBW. Furthermore, we found that physical hard work was found to increase the risk of LBW babies, which concurred with the findings of two Indian studies and one Nepalese studies, which showed hard physical work during pregnancy increased the risk of LBW babies [39-41]. In another study, it was suggested that higher energy expenditure might lower maternal nutrients and adversely impact birth weight [42]. Incremental risks of LBW have also been attributed to maternal socioeconomic and demographic 
factors $[17,43]$, possibly because socioeconomic conditions influence the use of essential maternal and child health services [44], maternal nutrition [45], and maternal decision-making power [46]. Our observation that female babies are more at risk of an LBW is supported by studies conducted in Kenya [47], Ethiopia [48,49], Nepal [20] and Australia [50].

Previous study reported male babies are less likely to have LBW, compared to their female counterparts because the male chromosome confers advantages in the determination of birth weight [51]. Interestingly, having access to a kitchen garden at home provides opportunities to increase dietary diversity and consume green leafy vegetables during pregnancy [52]. This study also revealed that mothers in the intervention area were found to be at a lower risk of having an LBW baby, indicating the beneficial effects of MATRI-SUMAN intervention [23] in lowering LBW cases.

We also found that a lack of utilization of essential prenatal care services was linked to LBW. A number of previous studies are in agreement with our finding of a positive association between LBW and poor utilization of prenatal care services, as indicated by low numbers of ANC visits $[18,20,32,33,53]$, non-consumption of IFA $[18,20,32]$ and de-worming tablets $[54,55]$, and no additional food intake [56,57] during pregnancy. An adequate number of antenatal visits aids the early recognition of pregnancy complications and promotes maternal nutrition and necessary care during pregnancy [58,59]. For example, an adequate consumption of IFA tablets reduces maternal anemia, the risks of pre-term birth and LBW [60], the consumption of de-worming tablets during pregnancy prevents worm infestation, and thereby, the proportion of LBW babies [54,61], and an extra meal taken during pregnancy ensures that the growing demand for calories during pregnancy, is met [62].

Previous studies have reported that mothers employed in the agricultural sector [63] have no maternal autonomy [3,46], are multi-parous [64], reside in a single-room apartment [65], have insufficient rest during pregnancy [66] and are at higher risk of giving birth to LBW babies. The univariate analysis conducted in the present study also demonstrated that mothers working in these sectors had a family income in the second tercile, an in-law/husband as the head of family, were multiparous, had an inadequate number of rooms in their homes, and had inadequate time for rest and sleep, were at higher risk of having an LBW baby. However, these associations disappeared after controlling for potential confounders in the multivariate regression analysis.

The present study was conducted to examine an important child healthcare problem faced by many developing countries and had a high response rate. However, our findings should be understood in the light of its pitfalls. First, data collection was conducted in a cross-sectional manner, which prevented investigation of causal relationships. Second, information on socioeconomic and maternal factors was self-reported, and thus, might be subject to bias. Third, although calibrated instruments were used, the different instruments were used to measure the facility-born and home-born (newborn) babies, and this may have influenced their birth weights. Fourth, this study was conducted in a small rural area of Nepal on a relatively small cohort, so special precautions should be taken to generalize our study findings. Nonetheless, a number of clusters from a rural community of Nepal was enrolled in the study, which we feel has policy implications.

\section{Conclusions}

Child survival policies and programs in Nepal aimed at improving child health outcomes should pay more attention to maternal and antenatal care service utilization factors. In our opinion bespoke maternal and child health programs, such as MATRI-SUMAN, a capacity-building and text-messaging intervention designed to improve maternal and child health outcomes, should be promoted. We suggest future studies to explore the determinants of small-for-gestational-age and pre-term births, and the economic feasibility of MATRI-SUMAN interventions in Nepal and other south Asian countries.

Author Contributions: D.A. and J.K.S. conceived the study design and performed the statistical analysis. D.A., J.K.S., R.K. wrote the manuscript and S.-J.Y., J.-H.P., and K.L. contributed substantially to the manuscript. All authors subsequently reviewed, revised, and approved the final version of the manuscript. 
Funding: This study received partial funding (logistics support) from Janaki Medical College Teaching Hospital (JMCTH) to implement the MATRI-SUMAN trial (Grant Number: RES-11-2072-73). The JMCTH did not contribute to the writing of this manuscript or to the decision to submit the manuscript for publication.

Acknowledgments: We thank Janaki Medical College Teaching Hospital (JMCTH) for the logistical support provided during the implementation of the MATRI-SUMAN trial and for the provision of analytical facilities.

Conflicts of Interest: The authors have no conflict of interest to declare.

\section{References}

1. Wardlaw, T.M. Low Birthweight: Country, Regional and Global Estimates; Unicef: New York, NY, USA, 2004.

2. United Nations Children's Fund (UNICEF). Low Birhtweight. Available online: https://data.unicef.org/ topic/nutrition/low-birthweight/ (accessed on 27 October 2018).

3. Singh, U.; Ueranantasun, A.; Kuning, M. Factors associated with low birth weight in nepal using multiple imputation. BMC Pregnancy Childbirth 2017, 17, 67. [CrossRef] [PubMed]

4. Lawn, J.E.; Cousens, S.; Zupan, J. 4 million neonatal deaths: When? Where? Why? Lancet 2005, 365, 891-900. [CrossRef]

5. Barros, F.C.; Barros, A.J.; Villar, J.; Matijasevich, A.; Domingues, M.R.; Victora, C.G. How many low birthweight babies in low- and middle-income countries are preterm? Rev. Saude Publica 2011, 45, 607-616. [CrossRef] [PubMed]

6. Kramer, M.S. Intrauterine growth and gestational duration determinants. Pediatrics 1987, 80, 502-511. [PubMed]

7. Qadir, M.; Bhutta, Z.A. Low birth weight in developing countries. In Small for Gestational Age; Karger Publishers: Basel, Switzerland, 2009; Volume 13, pp. 148-162.

8. Alderman, H.; Behrman, J.R. Reducing the incidence of low birth weight in low-income countries has substantial economic benefits. World Bank Res. Obs. 2006, 21, 25-48. [CrossRef]

9. Chen, W.; Srinivasan, S.R.; Yao, L.; Li, S.; Dasmahapatra, P.; Fernandez, C.; Xu, J.; Berenson, G.S. Low birth weight is associated with higher blood pressure variability from childhood to young adulthood: The bogalusa heart study. Am. J. Epidemiol. 2012, 1, S99-S105. [CrossRef] [PubMed]

10. Harding, J.E. The nutritional basis of the fetal origins of adult disease. Int. J. Epidemiol. 2001, 30, 15-23. [CrossRef] [PubMed]

11. Ediriweera, D.S.; Dilina, N.; Perera, U.; Flores, F.; Samita, S. Risk of low birth weight on adulthood hypertension-Evidence from a tertiary care hospital in a south asian country, sri lanka: A retrospective cohort study. BMC Public Health 2017, 17, 358. [CrossRef] [PubMed]

12. Larroque, B.; Bertrais, S.; Czernichow, P.; Leger, J. School difficulties in 20-year-olds who were born small for gestational age at term in a regional cohort study. Pediatrics 2001, 108, 111-115. [CrossRef] [PubMed]

13. Risnes, K.R.; Vatten, L.J.; Baker, J.L.; Jameson, K.; Sovio, U.; Kajantie, E.; Osler, M.; Morley, R.; Jokela, M.; Painter, R.C.; et al. Birthweight and mortality in adulthood: A systematic review and meta-analysis. Int. J. Epidemiol. 2011, 40, 647-661. [CrossRef] [PubMed]

14. Christian, P.; Murray-Kolb, L.E.; Tielsch, J.M.; Katz, J.; LeClerq, S.C.; Khatry, S.K. Associations between preterm birth, small-for-gestational age, and neonatal morbidity and cognitive function among school-age children in nepal. BMC Pediatr. 2014, 14, 58. [CrossRef] [PubMed]

15. Ashish, K.C.; Nelin, V.; Wrammert, J.; Ewald, U.; Vitrakoti, R.; Baral, G.N.; Malqvist, M. Risk factors for antepartum stillbirth: A case-control study in nepal. BMC Pregnancy Childbirth 2015, 15, 146.

16. Kramer, M.S. Determinants of low birth weight: Methodological assessment and meta-analysis. Bull. World Health Organ. 1987, 65, 663-737. [PubMed]

17. Sebayang, S.K.; Dibley, M.J.; Kelly, P.J.; Shankar, A.V.; Shankar, A.H.; Group, S.S. Determinants of low birthweight, small-for-gestational-age and preterm birth in lombok, indonesia: Analyses of the birthweight cohort of the summit trial. Trop. Med. Int. Health 2012, 17, 938-950. [CrossRef] [PubMed]

18. Gizaw, B.; Gebremedhin, S. Factors associated with low birthweight in north shewa zone, central ethiopia: Case-control study. Ital. J. Pediatr. 2018, 44, 76. [CrossRef] [PubMed]

19. Khanal, V.; Sauer, K.; Karkee, R.; Zhao, Y. Factors associated with small size at birth in nepal: Further analysis of nepal demographic and health survey 2011. BMC Pregnancy Childbirth 2014, 14, 32. [CrossRef] [PubMed] 
20. Khanal, V.; Zhao, Y.; Sauer, K. Role of antenatal care and iron supplementation during pregnancy in preventing low birth weight in nepal: Comparison of national surveys 2006 and 2011. Arch. Public Health 2014, 72, 2049-3258. [CrossRef] [PubMed]

21. Ministry of Health and Population; New ERA; ICF International. Nepal Demographic and Health Survey 2011; Ministry of Health and Population; New ERA: Kathmandu, Nepal; ICF International: Calverton, MD, USA, 2012.

22. Ministry of Health and Population; New ERA; ICF International. Nepal Demographic and Health Survey 2016; Ministry of Health and Population; New ERA: Kathmandu, Nepal; ICF International: Calverton, MD, USA, 2017.

23. Singh, J.K.; Kadel, R.; Acharya, D.; Lombard, D.; Khanal, S.; Singh, S.P. 'Matri-suman' a capacity building and text messaging intervention to enhance maternal and child health service utilization among pregnant women from rural nepal: Study protocol for a cluster randomised controlled trial. BMC Health Serv. Res. 2018, 18, 447. [CrossRef] [PubMed]

24. Singh, J.K.; Acharya, D.; Kadel, R.; Adhikari, S.; Lombard, D.; Koirala, S.; Paudel, R. Factors associated with smokeless tobacco use among pregnant women in rural areas of the southern terai, nepal. J. Nepal Health Res. Counc. 2017, 15, 12-19. [CrossRef] [PubMed]

25. Bennett, L.; Dahal, D.R.; Govindasamy, P. Caste ethnic and regional identity in nepal: Further analysis of the 2006 nepal demographic and health survey. Available online: https:/ / dhsprogram.com/pubs/pdf/FA58/ FA58.pdf (accessed on 13 August 2018).

26. Collins, J.W., Jr.; David, R.J. The differential effect of traditional risk factors on infant birthweight among blacks and whites in chicago. Am. J. Public Health 1990, 80, 679-681. [CrossRef] [PubMed]

27. Fang, J.; Madhavan, S.; Alderman, M.H. Low birth weight: Race and maternal nativity-Impact of community income. Pediatrics 1999, 103, e5. [CrossRef] [PubMed]

28. Kleinman, J.C.; Kessel, S.S. Racial differences in low birth weight. Trends and risk factors. N. Engl. J. Med. 1987, 317, 749-753. [CrossRef] [PubMed]

29. Bakewell, J.M.; Stockbauer, J.W.; Schramm, W.F. Factors associated with repetition of low birthweight: Missouri longitudinal study. Paediatr. Perinat. Epidemiol. 1997, 11 (Suppl. 1), 119-129. [CrossRef]

30. Acharya, P.P.; Alpass, F. Birth outcomes across ethnic groups of women in nepal. Health Care Women Int. 2004, 25, 40-54. [CrossRef] [PubMed]

31. Ojha, N. Maternal factors for low birth weight and preterm birth at tertiary care hospital. J. Nepal Med. Assoc. 2015, 53, 250-255. [CrossRef]

32. Habib, M.A.; Greenow, C.R.; Ariff, S.; Soofi, S.; Hussain, A.; Junejo, Q.; Hussain, A.; Shaheen, F.; Black, K.I. Factors associated with low birthweight in term pregnancies: A matched case-control study from rural pakistan. East. Mediterr. Health J. 2018, 23, 754-763. [CrossRef] [PubMed]

33. Tang, W.; Mu, Y.; Li, X.; Wang, Y.; Liu, Z.; Li, Q.; Li, M.; Scherpbier, R.; Guo, S.; Huang, X.; et al. Low birthweight in china: Evidence from 441 health facilities between 2012 and 2014. J. Matern.-Fetal Neonatal Med. 2017, 30, 1997-2002. [CrossRef] [PubMed]

34. Chanda, S.K.; Howlader, M.H.; Nahar, N. Educational status of the married women and their participation at household decision making in rural bangladesh. Int. J. Adv. Res. Technol. 2012, 1, 137-146.

35. Cribb, V.L.; Jones, L.R.; Rogers, I.S.; Ness, A.R.; Emmett, P.M. Is maternal education level associated with diet in 10-year-old children? Public Health Nutr. 2011, 14, 2037-2048. [CrossRef] [PubMed]

36. Dai, L.; Hu, W.; Luo, X.; Shen, Y. Interaction of prenatal care and level of maternal education on the risk of neonatal low birth weight. Zhonghua Liu Xing Bing Xue Za Zhi 2014, 35, 533-536. [PubMed]

37. Bates, L.M.; Maselko, J.; Schuler, S.R. Women's education and the timing of marriage and childbearing in the next generation: Evidence from rural bangladesh. Stud. Fam. Plan. 2007, 38, 101-112. [CrossRef]

38. Acharya, D.; Khanal, V.; Singh, J.K.; Adhikari, M.; Gautam, S. Impact of mass media on the utilization of antenatal care services among women of rural community in nepal. BMC Res. Notes 2015, 8, 345. [CrossRef] [PubMed]

39. Agarwal, K.; Agarwal, A.; Agrawal, V.; Agrawal, P.; Chaudhary, V. Prevalence and determinants of "low birth weight" among institutional deliveries. Ann. Niger. Med. 2011, 5, 48. [CrossRef]

40. Dickute, J.; Padaiga, Z.; Grabauskas, V.; Gaizauskiene, A.; Basys, V.; Obelenis, V. Do maternal social factors, health behavior and work conditions during pregnancy increase the risk of low birth weight in lithuania? Medicina 2002, 38, 321-332. [PubMed] 
41. Sharma, S.R.; Giri, S.; Timalsina, U.; Bhandari, S.S.; Basyal, B.; Wagle, K.; Shrestha, L. Low birth weight at term and its determinants in a tertiary hospital of nepal: A case-control study. PLoS ONE 2015, 10, e0123962. [CrossRef] [PubMed]

42. Jurewicz, J.; Hanke, W.; Makowiec-Dabrowska, T.; Kalinka, J. Heaviness of the work measured by energy expenditure during pregnancy and its effect on birth weight. Ginekol. Pol. 2006, 77, 537-542. [PubMed]

43. Bener, A.; Abdulrazzaq, Y.M.; Dawodu, A. Sociodemographic risk factors associated with low birthweight in united arab emirates. J. Biosoc. Sci. 1996, 28, 339-346. [CrossRef] [PubMed]

44. Celik, Y.; Hotchkiss, D.R. The socio-economic determinants of maternal health care utilization in turkey. Soc. Sci. Med. 2000, 50, 1797-1806. [CrossRef]

45. Ramakrishnan, U. Nutrition and low birth weight: From research to practice. Am. J. Clin. Nutr. 2004, 79, 17-21. [CrossRef] [PubMed]

46. Sharma, A.; Kader, M. Effect of women's decision-making autonomy on infant's birth weight in rural bangladesh. ISRN Pediatr. 2013, 12. [CrossRef] [PubMed]

47. Muchemi, O.M.; Echoka, E.; Makokha, A. Factors associated with low birth weight among neonates born at olkalou district hospital, central region, kenya. Pan Afr. Med. J. 2015, 20. [CrossRef] [PubMed]

48. Bugssa, G.; Alemayehu, M.; Dimtsu, B. Socio demographic and maternal determinants of low birth weight at mekelle hospital, northern ethiopia: A cross sectional study. Open J. Adv. Drug Deliv. 2014, 2, 609-618.

49. Asmare, G.; Berhan, N.; Berhanu, M.; Alebel, A. Determinants of low birth weight among neonates born in amhara regional state referral hospitals of ethiopia: Unmatched case control study. BMC Res. Notes 2018, 11, 447. [CrossRef] [PubMed]

50. Herceg, A.; Simpson, J.M.; Thompson, J.F. Risk factors and outcomes associated with low birthweight delivery in the australian capital territory 1989-90. J. Paediatr. Child Health 1994, 30, 331-335. [CrossRef] [PubMed]

51. Fisher, R.A. The evolution of dominance. Biol. Rev. 1931, 6, 345-368. [CrossRef]

52. Birdi, T.J.; Shah, S.U. Implementing perennial kitchen garden model to improve diet diversity in melghat, India. Glob. J. Health Sci. 2016, 8, 10. [CrossRef] [PubMed]

53. Khanal, V.; Scott, J.A.; Lee, A.H.; Karkee, R.; Binns, C.W. Factors associated with early initiation of breastfeeding in western nepal. Int. J. Environ. Res. Public Health 2015, 12, 9562-9574. [CrossRef] [PubMed]

54. Christian, P.; Khatry, S.K.; West, K.P., Jr. Antenatal anthelmintic treatment, birthweight, and infant survival in rural nepal. Lancet 2004, 364, 981-983. [CrossRef]

55. Larocque, R.; Casapia, M.; Gotuzzo, E.; MacLean, J.D.; Soto, J.C.; Rahme, E.; Gyorkos, T.W. A double-blind randomized controlled trial of antenatal mebendazole to reduce low birthweight in a hookworm-endemic area of peru. Trop. Med. Int. Health 2006, 11, 1485-1495. [CrossRef] [PubMed]

56. Wang, J.; Zeng, Y.; Ni, Z.M.; Wang, G.; Liu, S.Y.; Li, C.; Yu, C.L.; Wang, Q.; Nie, S.F. Risk factors for low birth weight and preterm birth: A population-based case-control study in wuhan, china. J. Huazhong Univ. Sci. Technol. Med. Sci. 2017, 37, 286-292. [CrossRef] [PubMed]

57. Shakya, K.L.; Shrestha, N.; Kisiju, P.; Onta, S.R. Association of maternal factors with low birth weight in selected hospitals of nepal. J. Nepal Health Res. Counc. 2015, 13, 121-125. [PubMed]

58. Mohamed Shaker El-Sayed Azzaz, A.; Martinez-Maestre, M.A.; Torrejon-Cardoso, R. Antenatal care visits during pregnancy and their effect on maternal and fetal outcomes in pre-eclamptic patients. J. Obstet. Gynaecol. Res. 2016, 42, 1102-1110. [CrossRef] [PubMed]

59. White, D.E.; Fraser-Lee, N.J.; Tough, S.; Newburn-Cook, C.V. The content of prenatal care and its relationship to preterm birth in alberta, canada. Health Care Women Int. 2006, 27, 777-792. [CrossRef] [PubMed]

60. Cogswell, M.E.; Parvanta, I.; Ickes, L.; Yip, R.; Brittenham, G.M. Iron supplementation during pregnancy, anemia, and birth weight: A randomized controlled trial. Am. J. Clin. Nutr. 2003, 78, 773-781. [CrossRef] [PubMed]

61. Urassa, D.P.; Nystrom, L.; Carlsted, A. Effectiveness of routine antihelminthic treatment on anaemia in pregnancy in rufiji district, tanzania: A cluster randomised controlled trial. East Afr. J. Public Health 2011, 8, 176-184. [PubMed]

62. Lechtig, A.; Habicht, J.P.; Delgado, H.; Klein, R.E.; Yarbrough, C.; Martorell, R. Effect of food supplementation during pregnancy on birthweight. Pediatrics 1975, 56, 508-520. [CrossRef] [PubMed]

63. Lima, M.; Ismail, S.; Ashworth, A.; Morris, S.S. Influence of heavy agricultural work during pregnancy on birthweight in northeast brazil. Int. J. Epidemiol. 1999, 28, 469-474. [CrossRef] [PubMed] 
64. Defo, B.K.; Partin, M. Determinants of low birthweight: A comparative study. J. Biosoc. Sci. 1993, 25, 87-100. [CrossRef] [PubMed]

65. Grimmer, I.; Buhrer, C.; Dudenhausen, J.W.; Stroux, A.; Reiher, H.; Halle, H.; Obladen, M. Preconceptional factors associated with very low birthweight delivery in east and west berlin: A case control study. BMC Public Health 2002, 2, 10. [CrossRef]

66. Koirala, A.K.; Bhatta, D.N. Low-birth-weight babies among hospital deliveries in nepal: A hospital-based study. Int. J. Womens Health 2015, 7, 581-585. [CrossRef] [PubMed]

(C) 2018 by the authors. Licensee MDPI, Basel, Switzerland. This article is an open access article distributed under the terms and conditions of the Creative Commons Attribution (CC BY) license (http:/ / creativecommons.org/licenses/by/4.0/). 